\title{
Criação e exploração de atividades interativas multimédia com um aluno portador do Síndrome de Down
}

\author{
Gustavo Carvalho, Manuel Meirinhos \\ Instituto Politécnico de Bragança - ESE
}

\begin{abstract}
Resumo
A utilização das tecnologias para promover o desenvolvimento e a aprendizagem de crianças com necessidades educativas especiais, requer por vezes uma dedicação exclusiva de diferentes intervenientes. As tecnologias multimédia podem revelar-se elementos de amplificação das capacidades humanas e instrumentos facilitadores, pela integração de vários sentidos na aprendizagem. Este trabalho baseou-se numa intervenção com uma criança portadora do Síndrome de Down, numa escola no norte de Portugal. Para a avaliação da intervenção seguiu-se a metodologia de estudo de caso. O aluno teve sucesso na realização das atividades que realizou, com empenho e motivação.
\end{abstract}

\section{Introdução}

Este estudo, foca-se na criação e exploração de atividades interativas multimédia com um aluno portador do Síndrome de Down - Regular. O aluno interveniente no estudo, tinha 14 anos e estava a frequentar o $8^{\circ}$ ano de escolaridade. O seu percurso escolar é constante e com aproveitamento. Segundo a Classificação Internacional de Funcionalidade (CIF) e o Artigo $1^{\circ}$ do Decreto - Lei 3/2008 de 7 de Janeiro, o aluno enquadra-se no perfil de funcionalidade de alunos com necessidades educativas especiais de carácter permanente, sinalizada no domínio cognitivo, por ser a problemática mais acentuada ao nível do seu funcionamento.

Neste trabalho procuramos envolver o aluno a dois níveis: o primeiro, na criação de recursos (fotografias) para integrar nas atividades multimédia e, num segundo nível, a realização das atividades multimédia. Procuramos trabalhar com elementos do quotidiano da criança, para que a aprendizagem se centrasse mais nas suas necessidades. As atividades tiveram assim por objetivo, motivar para a aprendizagem através da criação de um ambiente adequado às funcionalidades do aluno. Para isso recorremos ao uso de uma linguagem simples e familiar. Procuramos também que as atividades tivessem um grande reforço visual a fim de estimular a memória e a atenção.

Ao longo deste documento procuramos fazer uma contextualização das TIC na educação especial, descrevemos o estudo, os seus objetivos, a metodologia, o contexto geral do estudo, abordamos a criação e a modelação de recursos, a análise dos resultados e, por fim, fizemos uma síntese final.

\section{As TIC no contexto da educação especial}

As TIC têm um papel preponderante na educação. Esse papel poderá ser mais notório na educação especial. Segundo Sparrowhawk e Heald (2007), as TIC podem auxiliar a educação especial nos seguintes pontos: incrementam a motivação; melhoram o desempenho e aumentam espectativas; facilitam a diferenciação; procuram alternativas; promovem o envolvimento com o mundo real; facilitam o acompanhamento e a avaliação do professor; suportam a ligação do lar com a comunidade.

Todos os intervenientes no processo educativo devem estar em constante atualização, e todos se devem envolver no sucesso dos alunos, com, ou sem necessidades educativas especiais. A elaboração de um plano educativo tem de ter em conta a realidade de cada criança, a sua personalidade, a sua família, e toda a informação médica disponível, para assim o plano se adaptar melhor às suas características. Muitas vezes o insucesso da integração dos alunos com Síndrome de Down deve-se ao facto de os programas educativos não estarem adaptados. Estes alunos necessitam de mais prática e repetição dos exercícios, uma aprendizagem mais contextualizada e prática.

No contexto atual parece haver já escolas portuguesas que estão bem equipadas tecnologicamente. Também é inegável que muitos professores realizaram já formação no âmbito das necessidades educativas especiais, contudo a utilização das novas tecnologias, nomeadamente o multimédia, com crianças portadoras do Síndrome de Down, não está completamente explorada. A utilização das tecnologias para promover o desenvolvimento e a aprendizagem de crianças com necessidades específicas, requer por vezes uma dedicação exclusiva de diferentes intervenientes. A escola poderá não estar ainda adaptada a esta nova realidade, onde o trabalho em equipa parece ser fundamental.

Segundo Ponte (1992), a questão que se coloca não é apenas a atualização pedagógica da escola, mas sim, a sua organização em função de novas necessidades e de novos objetivos sociais. Os recursos, por vezes, existem e não são aproveitados, e já não serve a desculpa de que não há condições. Atualmente as novas tecnologias em contexto educativo são para o professor um novo desafio. A necessidade de formação é constante, pois a tecnologia não para de evoluir. O professor de educação especial é o recurso mais importante no processo de aprendizagem e 
pode incrementar a sua importância se fizer uso adequado das novas tecnologias. A falta de motivação por parte dos intervenientes e sucessivas alterações curriculares, provocadas por diretivas governamentais, atrasam e muitas vezes anulam a progressão de projetos individualizados que precisam de tempo para ser implementados corretamente.

Numa abordagem construtivista da utilização das TIC, julgamos muito importante o envolvimento do aluno, com necessidades educativas especiais, na construção da sua própria aprendizagem. O professor é um mediador em todo o processo, tornando-se fundamental no despertar do interesse e motivação do aluno. Uma forma de incentivar a aprendizagem dos alunos portadores do Síndrome de Down é a utilização de brinquedos e jogos interativos. A sua conceção tem de ter em conta as características da criança, quais as suas reais limitações e capacidades. Só assim podemos desenvolver um processo cognitivo adequado. O papel da família para uma evolução favorável da aprendizagem de uma criança com necessidades educativas especiais, é fundamental. A família é a base do desenvolvimento de uma criança com necessidades educativas especiais.

É observável em muitos estudos já realizados que é na educação especial que a integração das TIC obtém melhores resultados. Esta interligação família-escola-tecnologia parece-nos particularmente potenciadora de competências com crianças de necessidades educativas especiais.

Para a criação e implementação das atividades na sala de aula, Falconi \& Silva (2002), sugerem algumas estratégias:

- Dar ênfase a atividades relacionadas com a vida real do aluno;

- Manter uma rotina de trabalho;

- As atividades devem ser explicadas as vezes que forem necessárias;

- Utilizar o interesse que o aluno apresenta por determinados assuntos;

- Observar como o aluno age e reage em cada situação;

- Trabalhar em atividades que possam auxiliar o desenvolvimento de habilidades adaptativas: sociais, de comunicação, autonomia;

- Utilizar diferentes recursos;

- Adotar procedimentos pedagógicos que visem a descoberta do aluno;

- O aluno deve saber quando respondeu acertadamente, quando errou e, deve ser ajudado para que acerte na próxima vez;

- Trabalhar com o aluno a autocorreção das atividades; Proporcionar mais espaço de tempo entre a mudança de temas.

A utilização do multimédia parece-nos extremamente importante, uma vez que a comunicação se pode dirigir em vários sentidos, podendo a imagem, o áudio e o texto serem complementares para reforçar a informação. Por outro lado, o processo interativo gerado pelos documentos multimédia, obriga sempre a alguma “ginástica mental”.

\section{Descrição do estudo}

Nesta secção apresentamos os objetivos do estudo, a metodologia de trabalho e o contexto geral do estudo.

\section{Objetivos do estudo}

Neste projeto de investigação, como objetivo geral, procurou-se analisar e refletir de que forma a criação e exploração de atividades interativas multimédia, promovem a aprendizagem e a motivação do aluno no contexto escolar, através da construção de um ambiente de aprendizagem multimédia diferenciado e individualizado, onde o aluno foi parte integrante, através da coprodução dos conteúdos. Recorremos ao multimédia para podermos retirar vantagem da complementaridade comunicacional e procuramos envolver o aluno na construção dos recursos para a construção das atividades, pois sabemos também que a aprendizagem ocorre tanto melhor quanto mais a pessoa estiver envolvida e motivada na própria aprendizagem.

Com base no objetivo geral definimos 5 objetivos específicos, que nos permitiram determinar a sua consecução, através: da criação com sucesso dos recursos para a realização das atividades interativas multimédia; da verificação se a realização de recursos multimédia contribuiu para uma empatia com a aprendizagem escolar; da aferição se a elaboração de recurso multimédia e exploração de atividades contribuiu para a motivação da aprendizagem; da verificação da aquisição de conhecimentos na área das temáticas estudadas; da verificação da aplicação, em casa, das competências e o conhecimento adquirido na realização das atividades escolares.

\section{Metodologia}

Neste estudo é usado o método de investigação qualitativo, a recolha de dados é feita diretamente pelo investigador, no ambiente em que se desenvolveu o estudo, através de observação participante. O aluno é parte integrante no estudo, por esse motivo, a estratégia utilizada é o estudo de caso único.

Segundo diversos autores, o estudo de caso como metodologia de investigação, parece herdar características da investigação qualitativa, como o seu carácter holístico (Meirinhos \& Osório, 2010).

A recolha de dados é feita através de observação participante, com a ajuda de notas de campo, grelhas de observação e entrevistas semiestruturadas.

As notas de campo são um sistema de registo de dados, fruto da observação feita pelo investigador durante o contacto com o aluno. Estas, são o cerne da investigação, uma vez que descrevem a evolução das atividades e informam sobre o desenrolar da interação social do investigador e o investigado.

As grelhas de observação são construídas com base em indicadores pertinentes, são obtidas a partir da construção de um instrumento capaz de recolher ou produzir a informação prescrita pelos indicadores. As entrevistas semiestruturadas permitem uma obtenção mais rica de elementos de investigação, porque as características da entrevista, permitem uma maior proximidade entre investigador e entrevistado. 


\section{Contexto geral do estudo}

A primeira fase da investigação, depois de definidos os objetivos, foi o contacto com o Agrupamento de Escolas onde se realizou o estudo. Depois de entregue o requerimento de pedido de autorização para a observação de um aluno portador do Síndrome de Down na criação e realização de atividades interativas multimédia e da entrega do pedido de autorização ao encarregado de educação do aluno, iniciou-se o processo formal do projeto. Concordaram em participar as professoras de educação especial da escola, com as quais se planificou o plano de ação. A família da criança autorizou o estudo e apoiou todo o trabalho, demonstrou ter sido sempre uma família preocupada com o desenvolvimento da criança. Em relação à caracterização do aluno, segundo o relatório elaborado por uma das professoras de educação especial que participou no estudo, o aluno revela algumas competências ao nível da autonomia pessoal, social e na realização de atividades de cariz funcional:

- É independente nas rotinas diárias e nas AVD (atividades de vida diária);

- Identifica os sinais para peões (luminosos) e atravessa sempre nas passadeiras;

- Identifica locais públicos que têm utilidade para o seu dia-a-dia, localiza lojas e outros locais e entra e sai dos locais pelos sítios adequados atendendo às indicações existentes;

- É um jovem meigo, educado que executa os trabalhos que lhe são atribuídos;

- É persistente na realização das tarefas, no entanto, necessita de alguma supervisão;

- Estabelece com alguma facilidade relações interpessoais, com os colegas e com os adultos;

- Conhece e cumpre a maioria das normas de conduta ético-social na sala, recreio e comunidade;

- Utiliza com alguma regularidade formas de saudação e cortesia e participa nas atividades de grupo de forma adequada;

- Identifica situações corretas e incorretas.

O software escolhido para a modelação das atividades foi o EdiLim, que é um editor open source de atividades educativas, criado por Fran Macías. O EdiLim é composto pelo editor de atividades (EdiLim), pelo visualizador (LIM), e pelo ficheiro da base de dados (XML), este ficheiro XML permite definir as propriedades do livro, que é formado por um grupo de atividades. Depois de criadas, as atividades podem ser exportadas para HTML, o que permite a inserção num sítio da internet para posterior utilização por parte dos alunos.

\section{Criação e modelação das atividades}

Com a estratégia pedagógica definida, procedeu-se à definição do tipo de atividades a ser usadas no estudo, a Tabela 1 descreve o tipo de atividades escolhidas.
Tabela 1.Atividades escolhidas

\begin{tabular}{lc}
\hline Atividade & Descrição atividades \\
\hline 1 & $\begin{array}{c}\text { Consiste na correspondência de imagens de fruta com } \\
\text { palavras. }\end{array}$ \\
2 & $\begin{array}{c}\text { Consiste na resolução de um puzzle, com aproveitamento } \\
\text { dos recursos da atividade } 1 .\end{array}$ \\
3 & $\begin{array}{c}\text { Consiste na correspondência de imagens de moedas de } \\
\text { Euro, com imagens vetoriais de objetos. }\end{array}$ \\
4 & $\begin{array}{c}\text { Pretendeu-se que o aluno correspondesse as horas que lhe } \\
\text { foram indicadas de forma numérica, com imagens de } \\
\text { relógios com ponteiros. }\end{array}$ \\
5 & Consiste em relacionar imagens de animais com o som \\
& correspondente. \\
\hline
\end{tabular}

A criação de recursos (fotografias digitais) para as atividades foi feita pelo aluno em colaboração com o investigador. Todas as fotografias para as atividades foram feitas pelo aluno. Esta estratégia pareceu-nos importante, pois, para além de aprender a captar imagens, essas imagens podem, nas atividades, ser mais facilmente relacionadas.

A modelação foi feita à posteriori pelo investigador. As figuras 1, 2, 3, 4 e 5, mostra-nos o interface final das atividades.

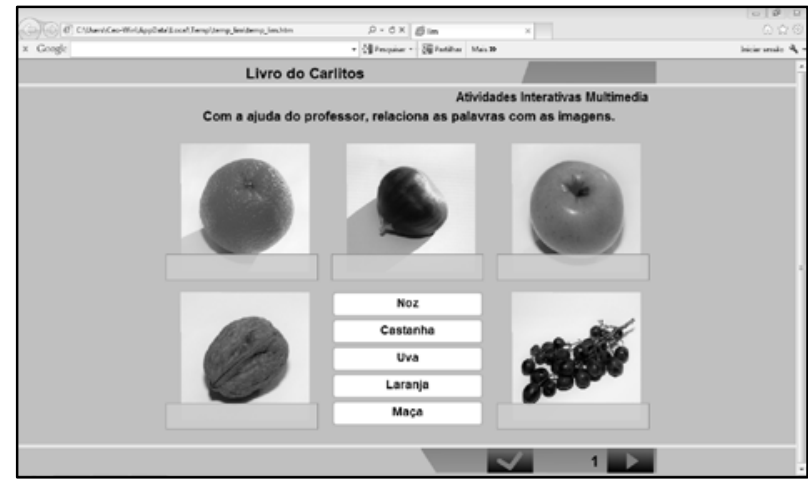

Figura 1. Correspondência entre palavras e imagem

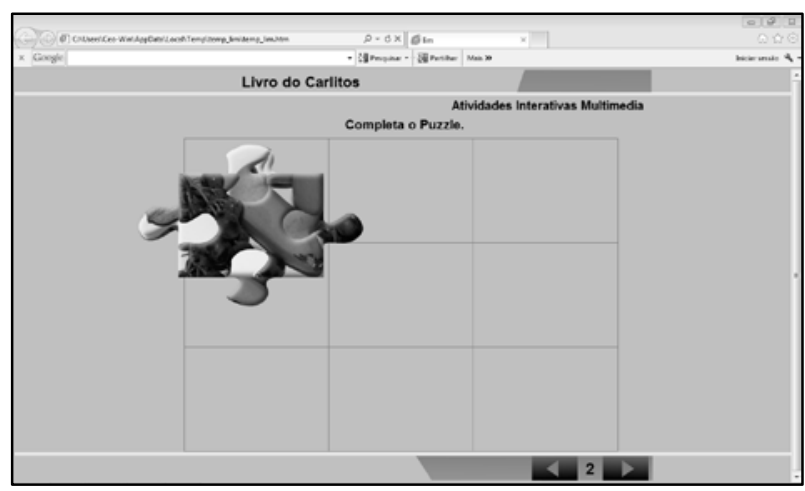

Figura 2. Realização de um puzzle 


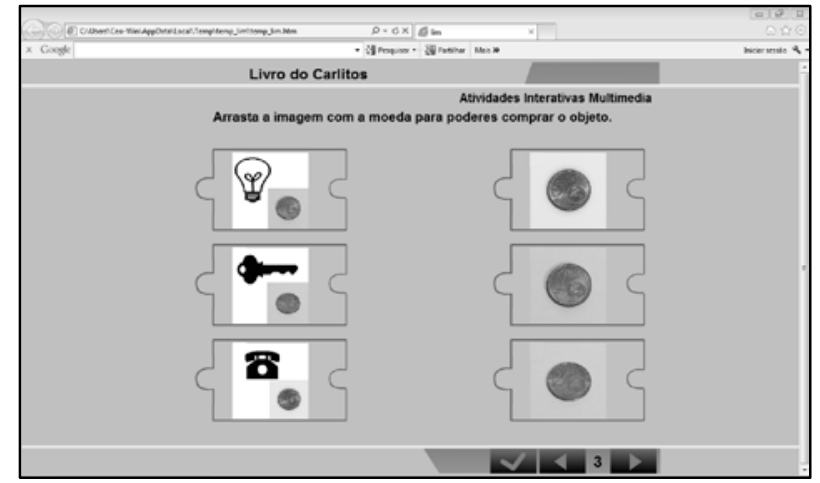

Figura 3. Atividade com moedas

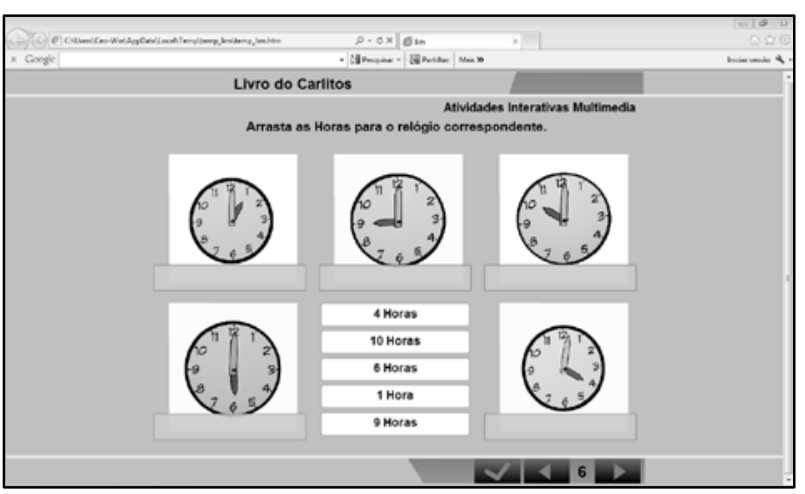

Figura 4. Atividade com horas

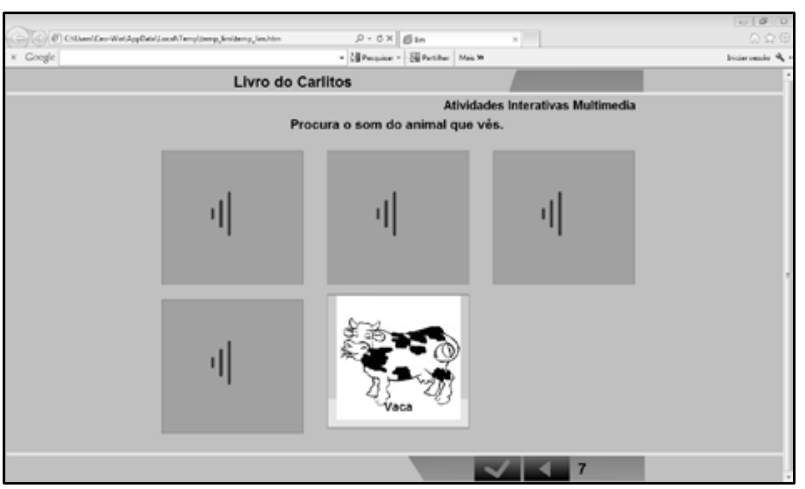

Figura 5. Associação de som e imagem

\section{Implementação das atividades com o aluno}

A última aula do estudo ficou reservada para a implementação das atividades.

Esta aula consistiu na execução, por parte do aluno, das atividades. O investigador foi observador participante, pois algumas atividades exigiram ajuda. Contudo essa ajuda foi apenas necessária na primeira interação com as atividades.

As atividades foram apresentadas num CD autoexecutável, para o aluno poder explorar as atividades sem restrições, apenas com o uso de um computador com browser instalado.

\section{Análise dos resultados}

Como referido anteriormente, o estudo foi dividido em 5 objetivos específicos. Em relação ao primeiro objetivo, criar com sucesso os recursos para a realização das atividades educativas multimédia, verificamos que o aluno resolveu esta tarefa com êxito. A criação dos recursos por parte do aluno permitiu-lhe estabelecer contacto com o conteúdo das atividades interativas multimédia, contribuindo para melhorar a sua aprendizagem aquando da realização das atividades multimédia. De acordo com a informação das entrevistas realizadas às professoras, verificamos que a criação dos recursos com sucesso por parte do aluno, o ajudaram na sua aprendizagem imediata. Estas referiram que em crianças portadoras do Síndrome de Down, o estímulo por meio de atividades lúdicas ajuda a prepará-las para a aprendizagem de habilidades mais complexas. Neste caso concreto, as manifestações de alegria por parte do aluno ao observar imediatamente o resultado das suas criações, dos recursos, mostram uma boa aceitação e entusiasmo na sua realização. $O$ aluno aprendeu rapidamente o processo de captação de imagem digital e, no final, as fotografias estavam bem enquadradas.

Em relação ao segundo objetivo, verificar se a realização de recursos multimédia contribui para uma empatia com a aprendizagem escolar, verificamos que, de acordo com a informação retirada das entrevistas das professoras, o facto de as atividades serem realizadas no ambiente natural e habitual do aluno (escola) e o facto de as atividades serem elaboradas com objetos comuns e direcionadas aos interesses do dia-a-dia do aluno, tornam-nas educativas e importantes para o seu quotidiano, revelando-se numa enorme vontade em realizar todas as tarefas. Algumas das ideias retiradas das notas de campo: “... a alegria do aluno foi enorme... a sua prontidão em fazer todas as atividades foi notória e contagiante...” Este entusiasmo foi notório ao longo da realização das atividades e mesmo no final, quando o aluno quis mostrar o seu CD ao diretor da escola. Era dele! Algo que ele tinha contribuído para produzir.

Em relação ao objetivo, aferir se a elaboração de recurso multimédia e exploração de atividades contribui para a motivação da aprendizagem, verificamos que a elaboração de recurso multimédia e a exploração de atividades contribuiu para a motivação da aprendizagem, uma vez que as atividades eram adequadas à realidade do aluno, abrangiam as necessidades a nível pessoal, intelectual e físico, ajudando à sua realização, felicidade, motivação e autonomia. A motivação do aluno era visível, pela prontidão e felicidade que este manifestava sempre que lhe era pedida uma tarefa e sempre que este a terminava.

Adquirir conhecimentos na área das temáticas estudadas foi um objetivo concretizado uma vez que o aluno resolveu quatro das 5 atividades multimédia sem ajuda, repetindo-as algumas vezes. Necessitou de ajuda numa atividade porque o aluno não sabe ler, mas identifica as letras.

Segundo as professoras, era evidente e notório a facilidade e rapidez com que a criança memorizava, percebia e identificava o que lhe era pedido. Esta forma de aprendizagem é facilitadora, motivadora e lúdica.

$\mathrm{O}$ facto de poder ser executada à velocidade da aprendizagem do aluno e o facto de poder ser repetida com regularidade, facilita a aquisição de conhecimentos por parte da criança portadora do Síndrome de Down. Este aspeto é importante pois estas crianças tem maior 
dificuldade de concentração e a aprendizagem é mais lenta que em crianças não portadoras. Durante a produção dos recursos e execução das atividades, a aquisição de conhecimentos por parte do aluno, traduziu-se na identificação do dinheiro, na identificação das horas e das diferentes atividades do dia, feitas a determinadas horas. Pode ainda conhecer diferentes frutas que podem eventualmente vir a fazer parte do seu quotidiano. Pode ainda aprender a fotografar e manusear objetos eletrónicos.

Aplicar, em casa, as competências e o conhecimento adquirido na realização das atividades escolares, foi um dos objetivos de maior cuidado e empenho por parte do investigador. O objetivo global do investigador foi facilitar e integrar as atividades no conhecimento diário da criança. A escolha das atividades e a forma de as executar está diretamente ligada a este objetivo, uma vez que os objetos escolhidos foram objetos comuns e que a criança tem acesso fácil em casa, o que poderá permitir à mesma reforçar a cada dia o conhecimento adquirido pela implementação das atividades. $\mathrm{O}$ facto de apenas ser necessário um computador com navegador para realizar as atividades facilita a que o aluno as possa repetir em casa. Pela análise da entrevista feita aos pais, este objetivo foi claramente atingido, uma vez que, logo no primeiro dia, que levou para casa o seu CD, fez uma surpresa à família e realizou em conjunto com eles todas as atividades. O aluno mostrou-se feliz por poder realizá-las em casa e por mostrar à família um projeto que ele realizou. Esta refere que quando chega uma visita a casa, tem de resolver as atividades, o que demonstra a importância deste tipo de projeto para estas crianças e, ao transpor para casa o projeto, este tornou-se mais duradouro.

\section{Em síntese}

Ao realizar este projeto tentamos adequar as atividades às competências e capacidades de aprendizagem do aluno. Procurou-se envolver o aluno a dois níveis: um primeiro nível baseado na criação dos recursos para integrar nas atividades e contribuir para a sua familiarização, e um segundo nível, a resolução das atividades interativas multimédia. Em relação à criação de recursos, o aluno realizou a tarefa com bastante êxito, quer no manuseamento da máquina fotográfica, quer no enquadramento das imagens. O entusiasmo do aluno era muito evidente e a empatia desenvolvida pela escola incrementou bastante, ao ponto de querer mostrar à comunidade educativa o trabalho por ele desenvolvido. A realização das atividades multimédia também se revelou uma tarefa relativamente fácil (excetuando uma atividade), pois o aluno já estava familiarizado com os recursos.

O multimédia parece poder desempenhar um papel preponderante na reabilitação destes alunos, através de formas de terapia interativas, visuais e sonoras. Uma das mais-valias desta tecnologia na educação especial é a adaptabilidade dos recursos educativos às necessidades de cada aluno, permitindo-lhe ampliar as suas competências em vários contextos.

\section{Referências}

Falconi, E. \& SILVA, N. (2009) Estratégias de Trabalho Para Alunos Com Deficiência Intelectual AEE. 2002. Disponível em: http://www.scribd.com/doc/12362 5277/Estrategias-pedagogicas-para-alunos-com-DI. Acedido em: 15/11/2012.

Glat, R. \& Pletsch, M. D. (2004). O papel da universidade frente às políticas públicas para educação inclusiva. Revista Benjamin Constant, N²9, p. 3-8, Rio de Janeiro.

Meirinhos, M. \& Osório, A. (2010). O estudo de caso como estratégia de investigação em educação. EDUSER: revista de educação, Vol. 2(2).

Ponte, J. P. (1992). Educação Matemática: Temas de Investigação. Lisboa: IIE.

Sparrowhawk, A. \& Heald, Y. (2007). How to use ICT to support children with Special Education Needs. Cambridge: LDA. 